\title{
Forum
}

\section{Bring the captive closer to the wild: redefining the role of ex situ conservation}

\author{
Diana J. Pritchard, Julia E. Fa, Sara Oldfield and Stuart R. Harrop
}

\begin{abstract}
In situ conservation is central to contemporary global biodiversity protection and is the predominant emphasis of international regulation and funding strategies. Ex situ approaches, in contrast, have been relegated to a subsidiary role and their direct contributions to conservation have been limited. We draw on a variety of sources to make the case for an enhanced role for ex situ conservation. We note the advances occurring within institutions specializing in ex situ conservation and stress that, although much remains to be done, many constraints are being addressed. We argue that the evidence of increasing extinction rates, exacerbated by climate change, challenges the wisdom of a heavy dependence on in situ strategies and necessitates increased development of ex situ approaches. A number of different techniques that enable species and their habitats to survive should now be explored. These could build on the experience of management systems that have already demonstrated the effective integration of in situ and ex situ techniques and hybrid approaches. For organizations specializing in ex situ conservation to become more effective, however, they will require tangible support from the institutions of global biodiversity governance. Resistance is anticipated because in situ conservation is entrenched through powerful groups and organizations that exert influence on global conservation policy and facilitate the flow of funding. The chasm that has traditionally divided in situ and ex situ approaches may diminish as approaches are combined. Moreover, the relentless loss of the 'wild' may soon render the in situ / ex situ distinction misleading, or even obsolete.
\end{abstract}

Keywords Botanical gardens, captive breeding, climate change, ex situ, in situ, zoos

Diana J. Pritchard (Corresponding author) University of Sussex, School of Global Studies, Sussex House, BN1 9RH, Sussex, UK. E-mail dp230@ sussex.ac.uk

Julia E. FA Durrell Wildlife Conservation Trust, Trinity, Jersey, Channel Islands, and Department of Life Sciences, Imperial College London, Silwood Park Campus, Ascot, UK

SARA OldField Botanical Gardens Conservation International, Richmond, Surrey, UK

StUART R. HARRop Durrell Institute of Conservation and Ecology, School of Anthropology and Conservation, University of Kent, Canterbury, UK

Received 19 July 2010. Revision requested 28 October 2010.

Accepted 9 December 2010. First published online 7 November 2011.

\section{Introduction}

T n situ and ex situ conservation are seen as two distinct 1 approaches to the protection of wild species. In situ conservation, defined by the Convention on Biological Diversity (CBD) with reference to the protection of species in their natural surroundings, derives primarily from scientific considerations concerning the conservation benefits that accrue from the protection of integrated habitats and ecosystems. Since the 1992 Earth Summit in Rio de Janeiro, Brazil, in situ conservation has been designated, expressly, as the legal and institutional priority. The CBD and other global instruments and funding strategies address a range of practices relating to in situ measures for conservation and relegate ex situ approaches to a subordinated supply role (CBD, 1992: Articles 8 \& 9).

We believe, however, that ex situ conservation has a more important role to play, especially in the face of the evidence of increasing extinction rates, exacerbated by climate change. We wish to stimulate discussions about the need to revise the contributions that ex situ approaches can make to conservation. Integrated conservation management approaches hold much potential but we must recognize the significance of institutional factors, not just the science, that have hitherto constrained the development of direct conservation contributions from ex situ and integrated techniques. We question the continued validity of the in situ / ex situ distinction.

\section{Increased capacity and continued constraints within ex situ institutions}

The vehicles of ex situ conservation are those organizations that hold wild plants and animals: zoos, aquaria, botanical gardens, arboreta and seed banks. Although these already lay claim to support conservation through a range of education, research and funding activities (Christie, 2010), their potential to contribute in more direct ways to the conservation of species has increased with recent developments. Specifically, these organizations and their networks have proliferated across the globe (BGCI, 2001; WAZA, 2005). For example, the International Species Information System is an international non-profit organization serving zoos and aquariums worldwide, and manages a comprehensive database of animal species and their environments for animal management and conservation goals. It records 
825 zoos and aquaria in 76 countries that exchange data on over 2 million captive animals of almost 15,000 taxa and 10,000 species.

Similarly, Botanic Gardens Conservation International (BGCI) manages a database with records of 2,561 botanic gardens worldwide, with 1,000 of these added in the last 10 years. These gardens cultivate $>80$,000 species in living collections, and increasingly hold seed banks and in vitro collections. Close to 700 botanic gardens have supplied collection data to BGCI for the global PlantSearch database that contains $>500,000$ records of c. 180,000 taxa. Facilities for storing and exchanging plant genetic material of cultivated crops have also expanded, primarily in response to the food security and resilience agenda, conforming, inter alia, to the requirements of the International Treaty on Plant Genetic Resources for Food and Agriculture. Whereas in the 1970 s 0.5 million samples were held in $<10$ gene banks, now $>6.1$ million samples are stored in 1,308 gene banks (FAO, 2009).

These represent infrastructural and professional advances to deal with challenges that have hitherto frustrated the capacities of ex situ facilities (Keller et al., 2002; Havens et al., 2006). Similarly, other earlier limitations of ex situ facilities to conserve species have been overcome given improved technical knowledge and practices with regard to collection strategies, genetic assessment, storage techniques and captive population management (Maunder \& Byers, 2005). Ex situ organizations have also accumulated a portfolio of direct, tangible impacts on conservation and performance indicators have been refined to measure this role (Havens et al., 2006). The world's botanic gardens contain $>12,000$ globally threatened plant species and c. 800 botanic gardens are managed with a specific focus on plant conservation (IUCN, 2002). Many botanic gardens also manage nature reserves and other forms of protected areas to combine ex situ methods with in situ plant conservation, and have increased engagement with local communities on livelihood issues, a key component of contemporary, holistic conservation strategies. Botanic gardens also play an important role in the implementation of the Global Strategy for Plant Conservation.

The ex situ breeding of animals or plants for direct conservation purposes has been frustrated by limited or conflicting organizational missions (Keller et al., 2002; Havens et al., 2006). But a further move away from the mere possession of extensive horticultural or exotic animal collections to one fulfilling a more active conservation role is thwarted by a lack of financial incentives. The largest source of international biodiversity funding, the Global Environmental Facility (the funding mechanism of the CBD), has no thematic or cross-cutting programme for ex situ activities.

How to balance the need, or preference, to generate revenue from visitor attraction with achieving direct conservation is a central and contentious theme within and amongst ex situ institutions. The financial pressure is perhaps less acute for botanical institutions as threatened plant species can be kept in a relatively straightforward and inexpensive manner (Kramer \& Havens, 2009; Oldfield, 2009). However, this dilemma is particularly challenging for zoos (Stanley Price \& Fa, 2007). Whilst claims and counter-claims abound regarding the nature and levels of support that zoos actually provide to conservation (Gusset \& Dick, 2010), sections of the zoo community (Fa et al., 2011) urge zoos to involve themselves more in the immediate task of saving greater numbers of species from extinction, and 'preserving wildlife...through field conservation initiatives' (Bonner, 2010) as part of their existing multifaceted portfolio of approaches to support conservation.

This more direct contribution can coexist with the other conservation support approaches that ex situ facilities currently employ. While it remains to be defined how this can be best achieved, in the case of zoos an immediate advance would be to focus on keeping more individuals of smaller threatened species and to coordinate effective captive-breeding programmes for them, given their higher breeding rates and lower maintenance costs. Evidence from European and North American animal collections (Fig. 1)
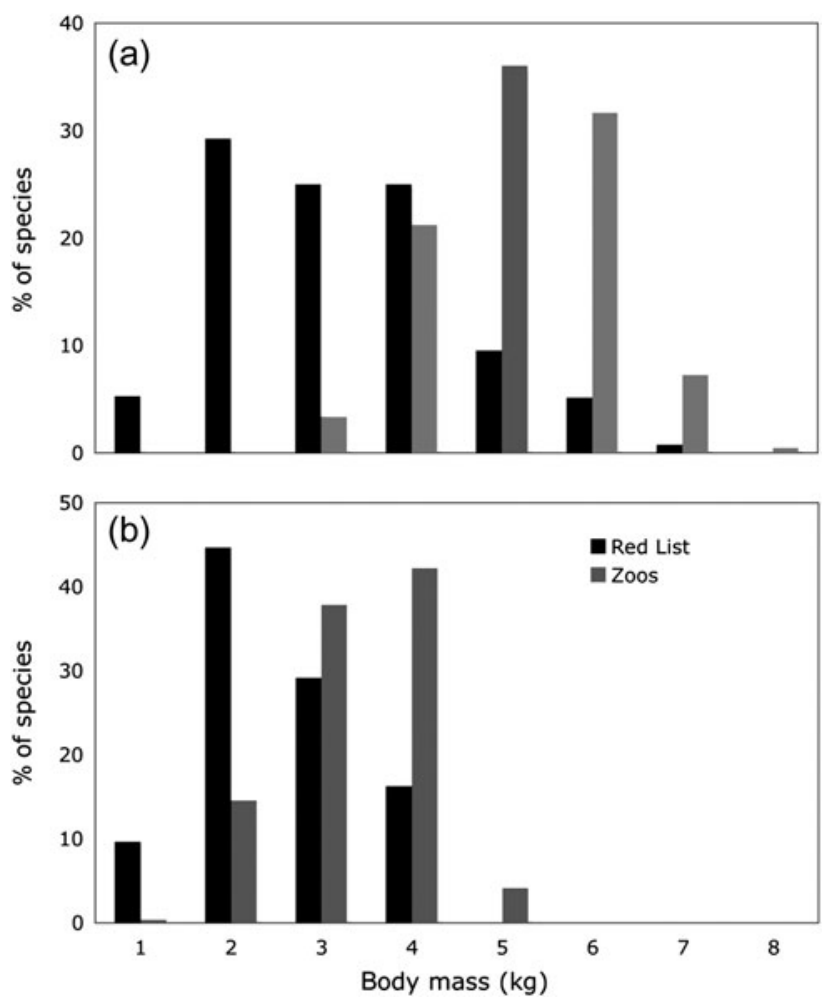

FIG. 1 Distribution of log body mass of (a) mammals and (b) birds on the IUCN Red List (Critically Endangered and Endangered; IUCN, 2011) compared to those held in captive breeding programmes by American and European zoo associations (Fa et al., 2011). Body mass data for extant birds from Dunning (2008) and for mammals from Smith et al. (2003). Species lists from AZA (2010) and EAZA (2010). 
demonstrates that this is not happening. The emphasis on large charismatic animals ( $\mathrm{Fa}$ et al., 2011) persists despite the lack of evidence that the public visit zoos primarily to see these species (Balmford et al., 1996).

Whereas international law and policy already deals with in situ conservation in relatively complex prescriptive provisions, frameworks that prescribe a meta-strategy for ex situ centres have not been developed. For example, although initiatives such as the European Union's Zoos Directive support ex situ strategies (EC Council Directive, 1999), and global documents, such as the World Association of Zoos and Aquariums Conservation Strategy, urge zoos to contribute to conservation, these fall short of effectively linking zoos into collaborative and strategic conservation activities (Rees, 2005). The impact of such initiatives is limited by the absence of effective international coordination, which necessarily, being a global issue, cannot be addressed by the array of regional associations and coordinated breeding programmes that currently exist. There is no centralized institutional mechanism to access and disseminate data on animal genetic resources within zoos similar to the Food and Agriculture Organisation's Domestic Animal Diversity Information System (FAO, 2009). This is a tool to conserve elements of global animal biodiversity even though it was established to manage animal genetic resources for food security and resilience strategies.

Despite remaining shortcomings ex situ conservation has an increasingly important role to play. Current circumstances, especially climate change, expose the vulnerability of our reliance on in situ approaches that seek to maintain natural systems and processes in specific geographical locations.

\section{Crises facing the in situ paradigm}

Projections of species distributions in scenarios of future climate indicate high numbers of species threatened by climate change alone (Thomas et al., 2004) or in conjunction with land-use changes (Jetz et al., 2007). Climatic and environmental change will compromise the ability of many species to survive unless they are able to adapt, disperse or migrate to other latitudes or altitudes. Species' ranges are shifting (Secretariat of the CBD, 2010), and those with specific habitat requirements and limited dispersal mechanisms are most vulnerable to extinction (Hawkins et al., 2008). Changes in climate will cause concomitant shifts in the viable geographical ranges for many species and habitats (Walther et al., 2002, 2005; Thuiller et al., 2006; Secretariat of the CBD, 2010) and species' ranges in the extreme polar areas and in high montane areas (from where many species cannot shift) are already receding (Thuiller, 2007). Although various models do not agree on the precise scope of these shifts, without human intervention fragile ecosystems may disappear altogether and some apparently robust ecosystems may shift geographical range and distribution (Bakkenes et al., 2002). Given this, protected areas may at some point in the future no longer harbour the species or habitats for which they were originally designated.

This scenario is exacerbated by the rapidity of climate change (Pounds et al. 1999; Jansen et al., 2007; Green et al., 2008; Gregory et al., 2009) and the ongoing fragmentation of habitats. Together, these processes inhibit migration processes and create barriers to species, preventing the colonization of new ranges or even adjoining habitats (Opdam \& Wascher, 2004). Conservation strategies that focus primarily on protected areas and habitat management will need to be reviewed.

These trends undermine the validity of key assumptions of the in situ paradigm. Because individual species respond differentially to climate change the underlying principle of in situ conservation-that site-specific ecosystem conservation ensures the protection of component speciesbecomes less compelling. Moreover, in a rapidly changing world the concept of natural may be outmoded, or at least in need of a re-conceptualization. The situation may call for drastic measures. At the very least we are challenged to define a new set of integrated ideas and practices so that we can shift to management systems that take into account the variety of conditions that lie between the extremes of a population entirely under human control and a freeranging population.

\section{Integrated approaches-not just rhetoric}

The use of management systems that effectively integrate in situ and ex situ techniques and processes into one framework is not a new approach. In the early 1980 s the concept of integrated management of threatened species was proposed in which a managed population comprised individuals held both ex situ and in situ (Foose, 1991a). Such populations are characteristically isolated, limited by their size and affected by chance variations in factors such as disease or loss of genetic diversity. Institutions deploying these approaches seek to maximize survival by interlacing knowledge about captive and wild populations to enhance management practices in accordance with the suggestions of some experts (Hanski \& Gilpin, 1991) and those proposing the theory of interactive meta-population management (Foose, 1991b; May, 1991; Stanley Price, 1991) There is more scope for further application of this type of expertise and theory to enhance wildlife management practices.

Hybrid in situ-ex situ strategies can also be appropriate in other instances. An example is where new populations of declining species are established within their former much larger range thus providing a 'reliable and cost effective hedge against extinction' (Burney \& Burney, 2007). The establishment of ex situ facilities within the range countries 
of threatened animal species also represents an important development and addresses ethical concerns regarding the removal of species from their country of origin. The successful reintroductions into the wild of, for example, the Mauritius kestrel Falco punctatus (Groombridge et al., 2000; Cade \& Jones, 2002), and Pygmy hog Porcula salvania (Narayan et al., 2008) suggest that the location of intensive management facilities within the species' habitat offers a productive way forward (Fa et al., 2011). In both cases free-living wild populations have been established from captive-bred animals. These arrangements add to the growing portfolio of experiences of the manipulation of the reproductive potential of wild pairs, captive propagation, and reintroduction or restocking of species in environments that are increasingly human-dominated.

If the ultimate goal of captive breeding is to re-establish new populations in the wild it is imperative for zoos and botanic gardens (irrespective of their existing support in other ways to conservation) to become more involved in the breeding and reintroduction of populations. Once there is scientific consensus on the conditions under which species should be moved from their known historical range these and other ex situ centres are likely to assume an important role in assisted migration and colonization, involving the translocation of species to more favourable habitats that they are unlikely to reach naturally. Assisted migration may be the only way to save some of the world's species (McLachlan et al., 2007).

There is already a shift in the recognition of ex situ conservation as a set of techniques that can support integrated management of wild and captive populations (Maunder \& Byers, 2005). Through its published guidelines on ex situ conservation, which are currently being revised, IUCN has stressed that such practices must be adopted because in situ conservation will not always be sufficient to ensure the long-term existence of many species (IUCN, 2002). However, the need to develop ex situ capacity further is not yet reflected in international discussions concerning future nature conservation strategies. For example, it is not mentioned in Global Biodiversity Outlook 3 (Secretariat of the CBD, 2010) as a future strategy nor was it on the agenda of the 2010 meeting of the Conference of the Parties to the CBD.

\section{Scope for change}

If the most important objective of the global conservation mission, to minimize extinctions, is to be coupled successfully with the wider global agenda, including food security and human health, then ex situ strategies can no longer be regarded as mere support mechanisms for in situ conservation. Emphasis must not only be on increasing the number of threatened species in ex situ collections but on assessing and ensuring the conservation value of such collections. For plants a major issue is that c. $33 \%$ of globally threatened plant species are cultivated only in one botanic garden. In addition, genetically representative collections are essential if they are to be used for recovery and restoration work (Sharrock et al. 2010). For animals there are known consequences of captive environments on morphology, behaviour and physiology that still need resolution but substantial improvements have being made on how animals should optimally be kept in captivity (Hosey et al., 2009).

Independently of debates concerning the scientific merits of ex situ approaches there are other entrenched obstacles to an enhanced role for ex situ techniques. Prevailing in situ conservation work is institutionalized through myriad public and private groups who operate at local, national and international levels. The large international organizations that characterize conservation science and practice exert influence on international conservation policy and facilitate the flow of funding (Fairhead \& Leach, 1998; Adams, 2004). Borrowing from policy analysis, we can appreciate how the interests of such groups (Haas 1997; Mosse 2005) of conservation organizations (Ladle \& Jepson, 2008) may become linked to the perpetuation of particular policy interventions around the in situ paradigm. Integrating techniques from both in situ and ex situ approaches may contribute to removing the professional chasm that has for so long divided ex situ and in situ specialists. The observation that agents of conservation during the 2oth century proved adept at modifying their approaches and strategies to improve conservation practice (Adams, 2004) provides a source of hope.

A key political consideration that has tempered the role of ex situ strategies since the negotiations leading up to the multilateral agreements defined at the 1992 Earth Summit has now been partly addressed. At that time biodiversity rich, usually developing nations were particularly concerned to retain sovereignty over their biological resources (Glowka et al., 1994), which reinforced the logic of the in situ focus. However, many range countries have now enacted strict access and benefit laws in line with CBD provisions that make it more difficult for commercially stronger nations to expropriate natural resources. To these ends, the 2010 Nagoya Protocol on Access to Genetic Resources and the Fair and Equitable Sharing and Benefits Arising from their Utilization (Secretariat of the CBD, 2010) should further reduce the need for the historic subordination of ex situ strategies.

Recognition of an expanded role for ex situ conservation techniques will necessarily involve a re-evaluation of accepted concepts and the related legal prescriptions concerning the meaning of what constitutes the range of a species. Range may become meaningless for those species for which predictions imply rapid and unpredictable perturbations in their former natural surroundings. This presents a profound challenge to the notion of in situ 
conservation and may result in the distinction between ex situ and in situ conservation blurring to the point of disappearing altogether. It is conceivable that a more nuanced appreciation may emerge that goes beyond this false dichotomy to identify instead how best to harness respective and complementary techniques.

\section{References}

Adams, W.M. (2004) Against Extinction: The Story of Conservation. Earthscan, London, UK.

AZA (Association of Zoos and Aquariums) (2010) Http://www. aza.org/ [accessed 1 July 2010].

Bakkenes, M., Alkemade, J.R.M., Ihle, F., Leemans, R. \& Latour, J.B. (2002) Assessing effects of forecasted climate change on the diversity and distribution of European higher plants for 2050. Global Change Biology, 8, 390-407.

Balmford, A., Mace, G.M. \& Leader-Williams, N. (1996) Designing the ark: setting priorities for captive breeding. Conservation Biology, 10, 719-727.

BGCI (Botanic Gardens Conservation International) (2001) Global Strategy for Plant Conservation. Secretariat of the Convention on Biological Diversity, Quebec, Canada.

Bonner, J. (2010) Opening Speech to AEZA Conference. http:// www.eaza.net/News/newsblog/Lists/Posts/Post.aspx?List = 59bc9bb5\%2Db623\%2D 468e \%2Dbbod\%2De21a42ec2f5a\&ID = 60 [accessed 24 January 2011].

Burney, D.A. \& Burney, L.P. (2007) Paleoecology and "inter-situ" restoration on Kaua'i, Hawai'i. Frontiers in Ecology and the Environment, 5, 483-490.

Cade, T.J. \& Jones, C.G. (2002) Progress in restoration of the Mauritius Kestrel. Conservation Biology, 7, 169-175.

CBD (Convention on Biological Diversity) (1993) ATS 32/1760 UNTS 79/31 ILM 818 [1992].

Christie, S. (2010) Why keep tigers in zoos? In Tigers of the World: The Science, Politics and Conservation of Panthera tigris (eds R. Tilson \& P. Nyhus), pp. 205-214. Elsevier, London, UK.

Dunning, J.B. (2008) CRC Handbook of Avian Body Masses. 2nd edition. CRC Press, Boca Raton, USA.

EAZA (European Association of Zoos and Aquaria) (2010) Http:// www.eaza.net/Pages/European\%20Association\%200f\%20 Zoos\%20and\%20Aquaria.aspx [accessed 1 July 2010]

EC Council Directive (1999) 1999/22/EC of 29 March 1999 relating to the keeping of wild animals in zoos. Official Journal L, 094, 09/04/ 1999, 0024-0026.

FA, J.E., Funk, S.M. \& O'Connell, D.M. (2011) Zoo Conservation Biology. Cambridge University Press, Cambridge, UK.

Fairhead, J. \& Leach, M. (1998) Reframing Deforestation. Global Analysis and Local Realities: Studies in West Africa. Routledge, London, UK.

FaO (Food and Agriculture Organisation) (2009) The State of the World's Plant Genetic Resources for Food and Agriculture. and edition. Food and Agriculture Organization of the UN, Rome, Italy.

Foose, T.J. (1991a) Viable population strategies for reintroduction programmes. In Beyond Captive Breeding; Re-introducing Captive Mammals to the Wild (ed J.W.H. Gipps), pp. 165-172. Clarendon Press, Oxford, UK.

Foose, T.J. (1991b) CBSG captive action plans. Captive Breeding Specialist Group News, 2, 5-7.

Glowka, L., Burhenne-Guilmin, F. \& Synge, H. (1994) A Guide to the Convention on Biological Diversity. Global Biodiversity Strategy
Environmental Law and Policy paper No 30. IUCN Environmental Law Centre, IUCN Biodiversity Programme, Gland, Switzerland.

Green, R.E., Collingham, Y.C., Willis, S.G., Gregory, R.D., Smith, K.W. \& Huntley, B. (2008) Performance of climate envelope models in retrodicting recent changes in bird population size from observed climatic change. Biology Letters, 4 , 599-602.

Gregory, R.D., Willis, S.G., Jiguet, F. Voříšek, P., Klvañová, A., VAn Strien, A. et al. (2009) An indicator of the impacts of climate change on European bird populations. PLoS One, 4, e4678. DOI: 10.1371/journal.pone.0004678

Groombridge, J.J., Jones, C.G., Bruford, M.W. \& Nichols, R.A. (2000) Conservation biology: 'ghost' alleles of the Mauritius kestrel. Nature, 403, 616.

Gusset, M. \& Dick, G. (2010) Biodiversity conservation projects supported by the world zoo and aquarium community. In Building a Future for Wildife: Zoos and Aquariums Committed to Biodiversity Conservation (eds G. Dick \& M. Gusset), pp. 57-6o. WAZA Executive Office, Gland, Switzerland.

HaAs, P.M. (ed.) (1997) Knowledge, Power, and International Policy Coordination. Studies in International Relations, University of South Carolina Press, Colombia, USA.

Hanski, I.A. \& Gilpin, M.E. (1991) Metapopulation dynamics: brief history and conceptual domain. Biological Journal of the Linnean Society, 42, 3-16.

Havens, K., Vitt, P., Maunder, M., Guerrant, E.O., Jr, \& Dixons, K. (2006) Ex situ plant conservation and beyond. BioScience, 56, 525-531.

Hawkins, B., Sharrock, S. \& Havens, K. (2008) Climate Change and Plants; Which Future? Botanic Gardens Conservation International, Richmond, UK.

Hosey, G., Melfi, V. \& Pankhurst, S. (2009). Zoo Animals: Behaviour, Management and Welfare. Oxford University Press, Oxford, UK.

IUCN (2002) Technical Guidelines in the Management of Ex Situ Populations for Conservation. IUCN, Gland, Switzerland.

IUCN (2011) The IUCN List of Threatened Species v. 2010.4. Http:// www.iucnredlist.org/[accessed 25 February 2011].

Jansen, E., Overpeck, J., Briffa, K.R., Duplessy, J.-C., Joos, F., Masson-Delmotte, V. et al. (2007) Palaeoclimate. In Climate Change 2007: The Physical Science Basis. Contribution of Working Group I to the Fourth Assessment Report of the Intergovernmental Panel on Climate Change (ed S. Solomon, D. Qin, M. Manning, Z. Chen, M. Marquis, K.B. Averyt et al.), pp. 433-498. Cambridge University Press, Cambridge, UK.

Jetz, W., Wilcove, D.S. \& Dobson, A.P. (2007) Projected impacts of climate and land-use change on the global diversity of birds. PLoS Biology, 5(6), e157.

Keller, T., Korn, H., Schmid, H. \& Weisser, C.F. (2002) Chances and Limitations of Ex Situ Conservation of Species and Genetic Diversity on a Global Perspective. Federal Agency for Nature Conservation, Bonn, Germany.

Kramer, A.T. \& Havens, K. (2009) Plant conservation genetics in a changing world. Trends in Plant Science, 14, 599-607.

Ladee, R. \& Jepson, P. (2008) Towards a biocultural theory of avoided extinction. Conservation Letters, 1, 111-118.

Maunder, M. \& Byers, O. (2005) The IUCN Technical Guidelines on the Management of Ex Situ Populations for Conservation: reflecting major changes in the application of ex situ conservation. Oryx, 39, 95-98.

MAY, R.M. (1991) The role of ecological theory in planning reintroduction. In Beyond Captive Breeding. Re-introducing Captive Mammals to the Wild (ed. J.W.H. Gipps), pp. 145-163. Clarendon Press, Oxford, UK. 
Mclachlan, J., Hellmann, J. \& Schwartz, M. (2007) A framework for debate of assisted migration in an era of climate change. Conservation Biology, 21, 297-302.

Mosse, D. (2005) Cultivating Development: An Ethnography of Aid Policy and Practice. Pluto Press, London, UK \& Ann Arbor, USA.

Narayan, G., Oliver, W.L.R., FA, J.E. \& Funk, S.M. (2008) Das zwergwildschwein. In Wilde Schweine und Flusspferde (eds A. Macdonald \& U. Ganslosser), pp. 203-223. Filander Verlag, Fürth, Germany.

OldFIELD, S.F. (2009) Botanic gardens and the conservation of tree species. Trends in Plant Science, 14, 581-583.

OPDAM, P. \& WASCHER, D. (2004) Climate change meets habitat fragmentation: linking landscape and biogeographical scale levels in research and conservation. Biological Conservation, 117, 285-297.

Pounds, J.A., Fogden, M.P. \& Campbell, J.H. (1999) Biological response to climate change on a tropical mountain. Nature, 398, 611-615.

REEs, P. (2005) The EC zoos directive: a lost opportunity to implement the convention on biological diversity. Journal of International Wildlife Law \& Policy, 8, 51-62.

Secretariat of the CBD (Convention on Biological Diversity) (2010) Global Biodiversity Outlook 3. Secretariat of the Convention on Biological Diversity, Montreal, Canada.

Secretariat of the CBD (Convention on Biological Diversity) (2011) Nagoya Protocol on Access to Genetic Resources and the Fair and Equitable Sharing of Benefits Arising from their Utilization to the Convention on Biological Diversity. Secretariat of the Convention on Biological Diversity, Montreal, Canada.

Sharrock, S., Hird, A., Kramer, A. \& Oldfield, S. (2010) Saving Plants, Saving the Planet-Botanic gardens and the implementation of GSPC Target 8. Botanic Gardens Conservation International, Richmond, UK.

Smith, F.A., Lyons, S.K., Ernest, S.K.M., Jones, K.E., Kaufman, D.M., DAYAN, T. et al. (2003) Body mass of late Quaternary mammals. Ecology, 84, 3403-3403.

Stanley Price, M. (1991) A review of mammal re-introductions, and the role of the Re-introduction Specialist Group of IUCN/SSC. In Beyond Captive Breeding: Reintroducing Endangered Mammals to the Wild (ed. J.H.W. Gipps), pp. 9-25. Symposia of the Zoological Society of London, No. 62. Clarendon Press, Oxford, UK.

Stanley Price, M. \& Fa, J.E. (2007) Reintroductions from zoos: a conservation guiding light or shooting star? Zoological Society of London. In Zoos in the 21st Century: Catalysts for Conservation? (eds A. Zimmermann, M. Hatchwell, L.A. Dickie \& C. West), pp. 155-177. Cambridge University Press, Cambridge, UK.

Thuiller, W. (2007) Biodiversity: climate change and the ecologist. Nature, 448, 550-552.

Thuiller, W., Broennimann, O., Hughes, G., Alkemade, J.R.M., Midgley, G.F. \& Corsi, F. (2006) Vulnerability of African mammals to anthropogenic climate change under conservative land transformation assumptions. Global Change $\mathrm{Bi}$ ology, 12, 424-440.

Thomas, C.D., Williams, S.E., Cameron, A., Green, R.E., Bakkenes, M., Beaumont, L.J. et al. (2004) Biodiversity conservation: uncertainty in predictions of extinction risk/effects of changes in climate and land-use/climate change and extinction risk (reply). Nature, 427, 145-148.

Walther, G.-R., Post, E., Convey, P., Menzel, A., Parmesan, C., BEEBEE, T.J.C. et al. (2002) Ecological responses to recent climate change. Nature, 416, 389-395.

Whlther, G., Berger, S. \& Sykes, M.T. (2005) An ecological 'footprint' of climate change. Proceedings of the Royal Society of London. Series B, Biological Sciences, 272, 1427-1432.

WAZA (World Association of Zoos And Aquariums) (2005) Building a Future for Wildlife-The World Zoo and Aquarium Conservation Strategy. World Association of Zoos and Aquariums, Bern, Switzerland.

\section{Biographical sketches}

DiAna PRITChARD's research interest focuses on global biodiversity conservation policy and transnational networks and communities. She advises on community-based conservation and has particular expertise in Latin America. Julia FA specializes in the biology of threatened species, zoo conservation biology and faunal overexploitation. SARA OLdFIELd is Secretary General of Botanical Gardens Conservation International and is interested in all aspects of plant conservation and the implementation of international biodiversity policy. Stuart Harrop is Director of the Durrell Institute for Conservation and Ecology, an interdisciplinary institution dealing with a wide range of applied conservation issues. His particular focus is international conservation policy and regulation. 